\title{
About Bilge Friedlaender
}

Written by: Mira Friedlaender

"Listening to the breeze and feeling it cool the warm sweat on my skin made me wonder. How can we express many different ways of perceiving the world? Is it possible to do it only with words, only with images, only with sound, only with movement? Are any one of these sufficient to express our experience of the world?"1

Bilge Friedlaender was an artist from Turkey, born 1934. She came to the USA aged 24 and lived her most productive years on the east coast, before returning to Istanbul several years before she died in 2000. She often spoke of living between cultures; a naturalized US citizen (late in life,) she stood out with her accented English, in Turkey, her spoken Turkish was sometimes elegantly out of date. As an artist, she lived on the edge of convention in both countries. Bilge interrogated her dual identities while living in the productive yet anguished space of 'between'.

Bilge created misleadingly ethereal, elemental works, aiming to embody "time, repetition, and the numerical mystery structure of things." ${ }^{2}$ She focused on simple materials, paper, pencil, watercolor, a twig or stone to communicate her complex seeking as an artist. Consider, Square Mutation: Denying Gravity \#10, 1975 (the artwork on the cover) - the restrained purity of line, color and shape, unexpectedly combined with found material, a pink strand of telephone wire; a line turned into a sqiggle, or a tube. Across a lifetime of artistic investigation, Bilge returned to the horizontal line and the square as expressions of human-ness, and our special connection to nature.

The artworks and writing she created reflect her complete focus on concepts of our perception of nature's structures, duality and relativity. Bilge wrote on this consistently, in later years from an eco-feminist position. Hers was an exsitensial seeking in order to reify the position of human beings as part of nature.

Part of Bilge's drive was to become part of the immortal discourse of creating. ${ }^{3}$ Working with the materials of her art, leaving her mark, connecting through material to the first cave painter's mark, was another. Touching things, mark making and writing gave an expression of her contemplation of the world, and our place in it.

\footnotetext{
${ }^{1}$ Bilge Friedlaender, Letter to Allen Ellenzwieg, March 20 ${ }^{\text {th }} 1978$

2 Bilge Friedlaender, Interview with Alan Sheldon (unpublished), 1977, Cambridge, MA

3 ibid
} 